Proceedings of the 18th National Conference on Superconductivity, Krynica Morska, Poland, October 8-13, 2017

\title{
Advances in Development of Powder-in-Tube $\mathrm{Nb}_{3} \mathrm{Sn}$, Bi-Based, and $\mathrm{MgB}_{2}$ Superconducting Conductors
}

\author{
B.A. GLOWACKI ${ }^{a, b, c, d, *}$ \\ ${ }^{a}$ Department of Materials Science and Metallurgy, University of Cambridge, \\ 27 Charles Babbage Road, Cambridge CB3 0FS, UK \\ ${ }^{b}$ Institute of Power Engineering, Mory 8, 01-330 Warsaw, Poland \\ ${ }^{c}$ Epoch Wires Ltd, Unit 8, Burlington Park, Foxton, Cambridge, CB22 6SA, UK \\ ${ }^{d}$ Department of Physics and Energy, Bernal Institute, University of Limerick, Castletroy, Ireland
}

\begin{abstract}
Analysis of the applicability of the low cost powder-in-tube technology of technical $\mathrm{Nb}_{3} \mathrm{Sn}_{2} \mathrm{Bi}_{2} \mathrm{Sr}_{2} \mathrm{CaCu}_{2} \mathrm{O}_{8+d}$ and $\mathrm{MgB}_{2}$ superconducting conductors has been presented in respect of their complexity in emerging hydrogen cryomagnetic technology where temperature of the liquid hydrogen can be as low as $14.1 \mathrm{~K}$, and all above conductors can be considered having a comparable $J_{c}(B, T)$ characteristics. The new emerging hydrogen economy where liquid hydrogen can serve as an energy carrier and cryogenic coolant with exceptionally high latent heat value presents opportunities for the range of superconducting materials characterised by $T_{c}$ applicable at hydrogen technologies. All above powder-in-tube conductors are exploring solid-liquid reactive diffusion processes originated from the complex compounds or intermetallics, defining the actual "technical price" in $(€ /(\mathrm{kA} \mathrm{m}))$ of the resulting wire compound based on $J_{c}(B, T)$ characteristics and materials as well as manufacturing cost and complexity. This rather complex techno-economic aspect of superconducting powder-in-tube conductors needs to be addressed and analysed to help to solve a trilemma concerning powder-in-tube conductors at low temperatures.
\end{abstract}

DOI: $10.12693 /$ APhysPolA.135.7

PACS/topics: 74.25.Sv, 74.25.Ld, 74.62.Fj

\section{Introduction}

The discovery of high temperature superconducting materials, HTS, and medium temperature superconducting material, MTS, $\left(\mathrm{MgB}_{2}\right)$, in 1986 and 2001 correspondingly and research on round powder-in-tube (PIT) conductors does not eliminate the old well-established Nb-based A-15 superconductors. In contrary, lack of the reliable strong, long lengths, high current round conductors operating at high magnetic field brought a renaissance to the Nb-based, mostly $\mathrm{Nb}_{3} \mathrm{Sn}$ PIT [1] and restacked-rod processed (RRP) [2] technologies for largescale applications in 21th century.

As the application of high specification $\mathrm{MgB}_{2}$ and $\mathrm{Bi}_{2} \mathrm{Sr}_{2} \mathrm{CaCu}_{2} \mathrm{O}_{8+d}$ superconductors gradually becomes a reality it is clear that incremental progress in the development of all superconducting PIT materials is the key to success of superconductivity applications at hydrogen temperatures in range of $14 \div 20 \mathrm{~K}$. Superconducting materials can only be applied according to an engineering specification that has to be determined for each particular application from the design requirements. Economic viability and operation and safety margins in service need to be taken into account as well. In this article, we will analyse three main PIT conductors $\mathrm{Nb}_{3} \mathrm{Sn}, \mathrm{MgB}_{2}$, and $\mathrm{Bi}_{2} \mathrm{Sr}_{2} \mathrm{CaCu}_{2} \mathrm{O}_{8+d}$ with potential of the implementation. Is our intention to bring discussion about priorities to be given cool most promising superconducting

*e-mail: bag10@cam.ac.uk
PIT conductor. $\mathrm{Nb}_{3} \mathrm{Sn}$ is characterised by lowest $T_{c} \approx$ $18 \mathrm{~K}$ but it is the most technologically established among three of them. $\mathrm{Bi}_{2} \mathrm{Sr}_{2} \mathrm{CaCu}_{2} \mathrm{O}_{8+d}$ has the highest critical temperature but $B(T)$ reversibility dependence makes this material useful below $\mathrm{LH}_{2}$ temperatures.

All three discussed above PIT conductors are exploring solid-liquid reactive diffusion processes originating from the complex compounds or intermetallics. One of the mayor drawback concerning resulting PIT wires is that the final superconducting core density cannot be reached due to or retrograde densification as it is in case of $\mathrm{Ag}-\mathrm{Bi}_{2} \mathrm{Sr}_{2} \mathrm{CaCu}_{2} \mathrm{O}_{8+d}$ or phase density difference due to phase transformation as it is for $\mathrm{MgB}_{2}$ and $\mathrm{Nb}_{3} \mathrm{Sn}$. The only realistic approach to achieve the dense highest quality superconducting core is to develop a reliable kinetic in situ thermo-mechanical densification technology. In this article, the evolution of research activity will be followed from near market industry driven design and development of fully engineered conductors through to research on basic and enabling science for materials processing that is largely academic and curiosity driven. The most effective path to application depends on a considered balance of research that is different for each conductor family depending on the state of maturity of the conductor processing route. As a consequence, the type of research activity appropriate for the development and optimisation of a particular "conductor of choice" processing route varies depending on the maturity of the technology as well. But also we need to bear in mind that emerging hydrogen cryomagnetic technologies will require operation of the PIT superconductors at $14 \div 20 \mathrm{~K}$ range [3]. 


\section{2. $\mathrm{Nb}_{3} \mathrm{Sn}$ powder-in tube multifilament conductor}

Historically, the first PIT conductors were manufactured using variety of combinations of $\mathrm{Cu}$ and $\mathrm{Nb}$ powder mixture which was subsequently infiltrated or interdiffused by $\mathrm{Sn}$ to form $\mathrm{Nb}_{3} \mathrm{Sn}$ conductors [4]. These processes however scientifically interesting are complex and very difficult to scale up.

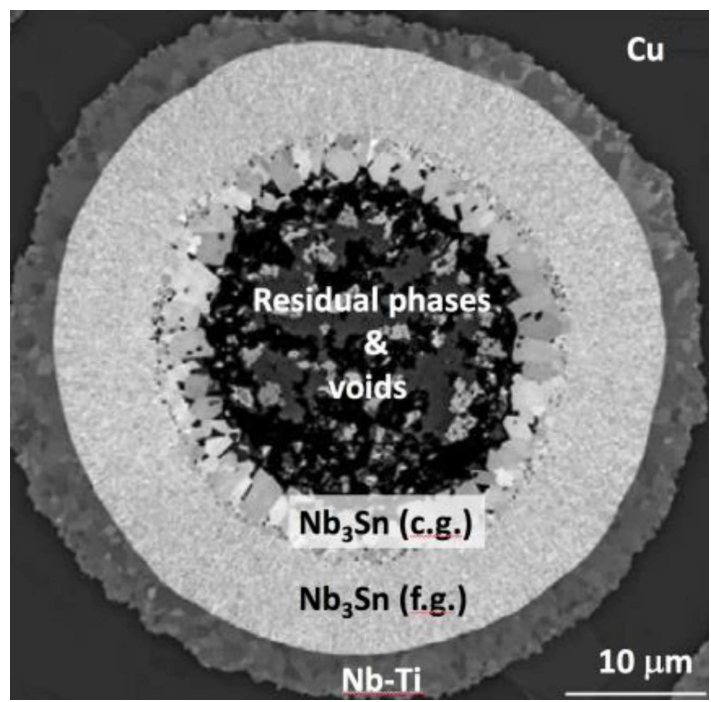

Fig. 1. Transverse cross-section of a single tubular filament after reaction of a 192-filamentary PIT $\mathrm{Nb}_{3} \mathrm{Sn}$ conductor manufactured by Bruker EAS. In the centre, marked as "residual phases" there is a core made of large $\mathrm{Nb}_{3} \mathrm{Sn}$ grains (light contrast), $\mathrm{Cu}$-rich phases (dark contrast) and large irregular voids (black). The " $\mathrm{Nb}_{3} \mathrm{Sn}$ (c.g.)" represents layer of coarse grains of $\mathrm{Nb}_{3} \mathrm{Sn}$ followed radially by a thick annulus of fine grain $\mathrm{Nb}_{3} \mathrm{Sn}$ marked as " $\mathrm{Nb}_{3} \mathrm{Sn}$ (f.g.)". The grey ring represents the residual Nb7.5 wt\% Ta tube which acts as also residual diffusion barrier between intermetallic superconducting layer and $\mathrm{Cu}$ stabilising matrix. One may realise that the only " $\mathrm{Nb}_{3} \mathrm{Sn}$ (f.g.)" ring is conducting an effective critical current. Adopted after Tarantini et al. [5].

Recent years an intensive research on PIT $\mathrm{Nb}_{3} \mathrm{Sn}$ conductors using initial powder mixture of $\mathrm{NbSn}_{2}, \mathrm{Sn}$ and $\mathrm{Cu}$ inserted in $\mathrm{Cu}$-clad Nb7.5 wt\% Ta tube where the powder was separated from the tube by a thin $\mathrm{Cu}$ sleeve results in exceptionally high $J_{c}$ of a very fine $\mathrm{Nb}_{3} \mathrm{Sn}$ layer formed [5], see Fig. 1. Process is rather very complex where 4-stage heat treatment is used to provide the finest structure of $\mathrm{Nb}_{3} \mathrm{Sn}$ conductor. Such a multistage complex heat treatment of intermetallic $\mathrm{NbSn}_{2}$ powder in presence of $\mathrm{Cu}, \mathrm{Sn}$ and $\mathrm{Nb}$ results in formation of the range of intermediated phases such as: $\mathrm{Cu}_{6} \mathrm{Sn}_{5}, \mathrm{Cu}_{3} \mathrm{Sn}$, $\mathrm{Nb}_{6} \mathrm{Sn}_{5}$ before the final $\mathrm{Nb}_{3} \mathrm{Sn}$ layer is formed [5].

However, a substantial improvement of $J_{c}(B)$ at $4.2 \mathrm{~K}$ of state of the art powder-in-tube niobium-tin superconductors is well documented, see Fig. 2 [1], but there are three major draw backs: firstly, there is no change in

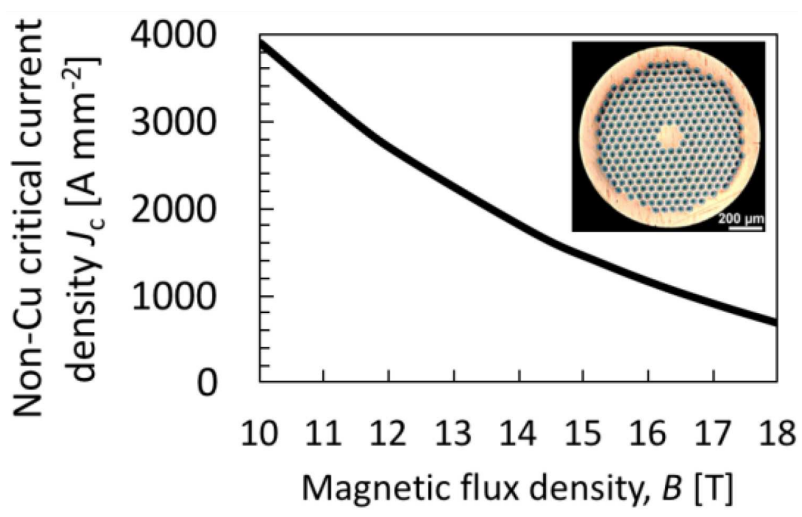

Fig. 2. Non-Cu critical current density as function of magnetic flux density at $4.2 \mathrm{~K}$ for 288 filament PIT wire diameter $1.255 \mathrm{~mm}$, manufactured by ShapeMetal Innovation. After Godeke et al. [1]. Individual filaments are approximately $35 \mathrm{~mm}$ in diameter, where $\mathrm{Cu}$ constitutes for $55 \%$ of the overall cross-section of the wire. Non-copper data is specifically used in comparison of the performance of the actual superconducting portion of " $\mathrm{Nb}_{3} \mathrm{Sn}$ conductors" due to wide variation of the superconductor to $\mathrm{Cu}$-cryostabiliser ratio used by industrial manufacturers. The presented non- $\mathrm{Cu} J_{c}$ value corresponds to $I_{c}$ divided by the sum of surfaces of cross-section of the total number of individual filaments. In case of the engineering critical current density, $J_{\text {ceng }}$, presented in plot critical current values will be reduced by $\approx 55 \%$.

a grain-boundary pinning mechanism described by general equations, Eq. (1) and Eq. (2) of the $\mathrm{Nb}_{3}$ Sn layers which will not shift the maximum pinning force towards the higher magnetic flux density [6]:

$$
\begin{aligned}
& F_{p}=J_{c} B=G \frac{\left(B_{c 2}(T)\right)^{n}}{k^{m}} f(b) \\
& f(b)=b^{p}(1-p)^{q}
\end{aligned}
$$

where constant $G$ is a geometrical factor of the microstructure (usually interpreted as a surface area of inclusion per unit volume of matrix), $n$ and $m$ are fitting parameters, $k$ is smoothing parameter defining maximum pinning value, and $p$ and $q$ are pinning and materials related parameters. The position of the maximum of the pinning force on the reduced flux density $b=B / B_{c 2}$ is defined by the ratio $p /(p+q)$, and for the particular wire presented in Fig 2: $p=0.5$ and $q=2$, which are typical values for grain boundary pinning; $B_{c 2}$ is estimated to be $25.5 \mathrm{~T}$ at LHe. Secondly, there is a central porous core in every filament which contains residual phases and $30 \%$ of irregularly distributed voids. (Such voids formation as in all PIT superconductors introduce structurally unsupported core which if exposed to high Lorentz forces is susceptible to degradation of the material and consequently catastrophic reduction of $J_{c}$ ). Thirdly, and probably the most decisive factor is that manufacture of the initial $\mathrm{NbSn}_{2}$ powders for PIT wires is extremely expensive making this process not economic despite very high $J_{c}(B)$ characteristics in comparison with RRP technology [2]. 
Grain boundary pinning related mechanism is difficult to change, however there are new possible elaborated approaches that can be further developed $[6,7]$. The voids formation in the central core cannot be avoided but can be reduced by implementation of combination of the compositional and architectural changes in the initial filamentary core and also by application of in situ external pressure during sintering as it will be discussed in the following sections concerning Bi-based and $\mathrm{MgB}_{2}$ PIT superconductors. On the other hand, costly manufacture of $\mathrm{NbSn}_{2}$ powders can be overcome more easily with low cost intermetallic manufacture technology. It is obvious that use of the expensive high purity, high melting temperature $\mathrm{Nb}$ metal $\left(\approx 2500^{\circ} \mathrm{C}\right)$ and low temperature melting temperature $\mathrm{Sn}\left(232^{\circ} \mathrm{C}\right)$ to produce $\mathrm{Nb}_{2} \mathrm{Sn}$ powders presents a challenge. Complex processing and fine powder fabrication methods, makes the overall cost of conventional PIT $\mathrm{Nb}_{3} \mathrm{Sn}$ superconductors exceptionally high. A novel electrochemical process was proposed where powder $\mathrm{Nb}_{3} \mathrm{Sn}$ superconducting material can be synthesized directly from respective oxide precursors, instead of the high purity metals by means of the solid-state electrode-oxidation method [8]. An example of a simple reduction of $\mathrm{Nb}_{2} \mathrm{O}_{5}$ to spherical $\mathrm{Nb}$ powder is presented in Fig. 3.

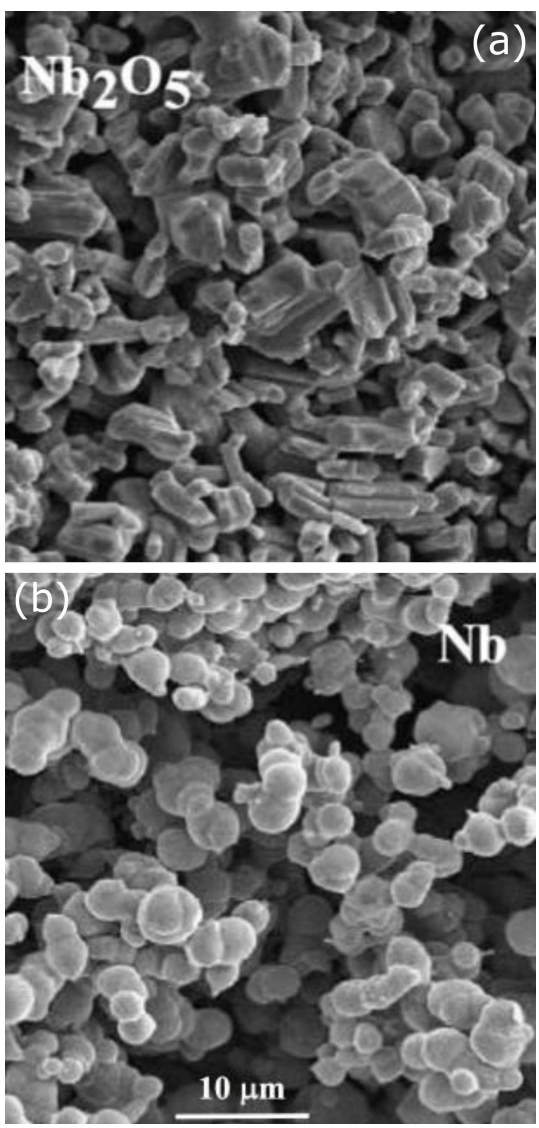

Fig. 3. SEM images of the fractured surfaces representing morphology of the (a) $\mathrm{Nb}_{2} \mathrm{O}_{5}$ and resulting $\mathrm{Nb}$ metal powder, (b) with spherical particles, after electrochemical reduction [9].
This technique is based on the concept of cathodic oxygen ionisation [10]. The new process of making $\mathrm{Nb}_{3} \mathrm{Sn}$ conductors is straightforward, less energy intensive, environmentally friendly, and at low operating temperature and low-cost [11]. The same electrochemical reduction can be used to form other superconducting $\mathrm{NbSn}_{2}$ or $\mathrm{Nb}_{6} \mathrm{Sn}_{5}$ intermetallics from stoichiometric oxide powders to achieve low cost desired $\mathrm{NbSn}_{2} / \mathrm{Nb}_{6} \mathrm{Sn}_{5}$ powder morphology product, making manufacture of the $\mathrm{Nb}_{3} \mathrm{Sn}$ PIT conductors economically competitive with half price of current $10 € /(\mathrm{kA} \mathrm{m})$ at $12 \mathrm{~T}$ and $4.2 \mathrm{~K}$ [12]. Such price can be lowered further if upscaling of the production takes place but it will increase dramatically if the operating temperature of the superconductor is in range of $14 \mathrm{~K}$.

\section{3. $\mathrm{Ag}-\mathrm{Bi}_{2} \mathrm{Sr}_{2} \mathrm{CaCu}_{2} \mathrm{O}_{8+d} \mathrm{PIT}$ multifilamentary conductor}

$\mathrm{Bi}_{2} \mathrm{Sr}_{2} \mathrm{CaCu}_{2} \mathrm{O}_{8+d}$ is the only cuprate superconductor that can be made into a round-wire silver matrix conductor with a critical current density $J_{c}$ over $10^{5} \mathrm{~A} \mathrm{~cm}^{-2}$ at $4.2 \mathrm{~K}$. But as it was well documented in literature $\mathrm{Bi}_{2} \mathrm{Sr}_{2} \mathrm{CaCu}_{2} \mathrm{O}_{8+d}$ experiences a unique retrograde densification process in the temperature range $850 \div 890^{\circ} \mathrm{C}[13]$. Presence of metallic silver interface lowers the binding energy of the Bi-compound accelerating surface diffusion processes as well accelerates formation of thin plate-like single crystallites that grow in a randomly oriented fashion [14] (known as retrograde densification), thus distorting originally precisely manufactured filamentary architecture as presented in Fig. 4. This retrograde densification, coupled with a narrow sintering range [15] and strict oxygen engineering in proximity of the melting temperature [16] makes this compound a difficult one to process.

The resulting microstructure of multifilamentary $\mathrm{Ag}-\mathrm{Bi}_{2} \mathrm{Sr}_{2} \mathrm{CaCu}_{2} \mathrm{O}_{8+d}$ before sintering looks very regular, see Fig. 4a, whereas after sintering filaments present a very open microstructure with numerous overgrowths bridging filaments and random voids resulting from cuprate migration corresponding to final overall $60-70 \%$ density of the superconducting filaments, see Fig. $4 \mathrm{~b}$ causing significant reduction of $I_{c}(B, T)$ characteristics.

The only solution to this problem is application of external pressure. There are two methods used: one is by increase the density of the filaments after drawing using $2 \mathrm{GPa}$ of cold isostatic pressure resulting in almost doubling the $I_{c}$ value, however considering value of the pressure induced before sintering this has no very pronounce effect on the suppression of the retrograde densification [17]. The other more accessible and effective method was to use the hydrostatic gas pressure of $20 \div 100$ atm during sintering up to $887^{\circ} \mathrm{C}$ that effectively suppressed retrograde densification resulting in $100 \%$ dense filaments characterised by dramatically improved $I_{c}$ almost an order of magnitude [18]. The fact that such a low pressure was sufficient to transfer pressure via metal matrix was that silver meting point is 

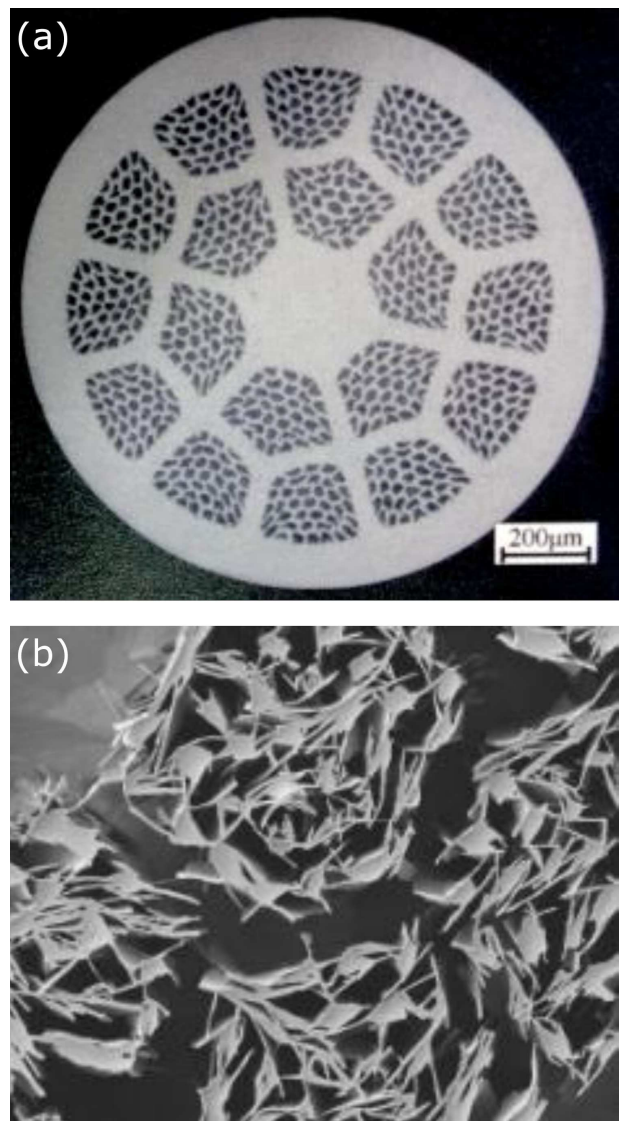

Fig. 4. (a) Image of multifilamentary $\mathrm{Ag}-\mathrm{Bi}_{2} \mathrm{Sr}_{2} \mathrm{CaCu}_{2} \mathrm{O}_{8+x}$ conductor (18 bundles each containing 37 filaments) in silver matrix before sintering, (b) image of etched silver matrix inter-bundles region after reaction showing result of retrograde densification. Courtesy of L. Motowidlo.

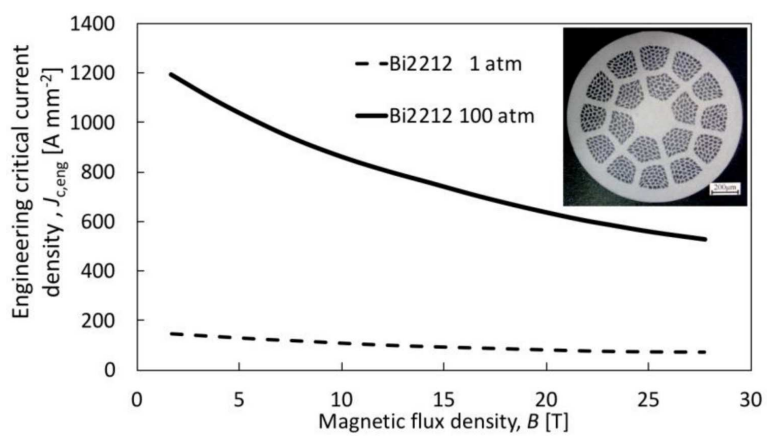

Fig. 5. Improvement of transport engineering critical current density $J_{c, \text { eng }}$ value of $\mathrm{Ag}-\mathrm{Bi}_{2} \mathrm{Sr}_{2} \mathrm{CaCu}_{2} \mathrm{O}_{8+d}$ conductor at $4.2 \mathrm{~K}$, sintered under pressure of $100 \mathrm{~atm}$. Complexity of the retrograde densification of superconducting filaments and their complex morphology makes comparative $J_{\text {ceng }}$ measurements more reliable. (Engineering critical current density is defined as division of $I_{c}$ over total cross-section of the conductor.) It is evident that $J_{c, e n g}$ has increased almost an order of magnitude, outperforming $\mathrm{Nb}_{3} \mathrm{Sn}$ PIT conductor above $17 \mathrm{~T}$. The high $J_{c}$ at high magnetic flux density can only be achieved at LHe temperature whereas the $J_{c}(B)$ performance at $20 \mathrm{~K}$ is comparable to $\mathrm{MgB}_{2}$. After Larbalestier et al. [18]. $\approx 960{ }^{\circ} \mathrm{C}$ and the softening of the $\mathrm{Ag}$ matrix at sintering temperature of a $\mathrm{Ag}-\mathrm{Bi}_{2} \mathrm{Sr}_{2} \mathrm{CaCu}_{2} \mathrm{O}_{8+x}$ conductor was only 70 degrees below $\mathrm{Ag}$ melting temperature. It becomes evident that combined thermo-mechanical densification process at moderated pressure (in case of soft easy deformable Ag-based matrix) is most effective method to achieve the outstanding densified of round wires for applications at very high magnetic flux densities $\approx 30 \mathrm{~T}$ at $4.2 \mathrm{~K}$, Fig. 5 .

Of course, one may question the mechanical strength of such silver-based matrix wires exposed to ultra-high Lorentz forces at $30 \mathrm{~T}$, but it is a separate issue, since silver or silver alloys must be used (as an oxygen conductors) to enable optimisation of the oxygen engineering in such wires [16]. Time/temperature dependent pressing procedure following Ashby deformation maps has been also used to successfully increase the density of bulk Bi2223 samples [19], that suffer less pronounced but similar retrograde densification as $\mathrm{Bi}_{2} \mathrm{Sr}_{2} \mathrm{CaCu}_{2} \mathrm{O}_{8+d}$. This was an inspiration for development of overpressure densification of multifilaments in Ag-Bi2223 tapes. In this process application of controlled overpressure sintering (CT-OP) (at pressure of $300 \mathrm{~atm}$ and $900^{\circ} \mathrm{C}$ ) enables achieving a very dense, well-interconnected superconducting core in the individual filaments [20]. Such a procedure enhanced the critical current by $50 \%$ if compared to conventional Bi-2223 wires sintered in atmospheric pressure, and most importantly that voids disappeared almost completely in the CT-OP processed specimens. To conclude, the detrimental effect of retrograde densification of round PIT $\mathrm{Ag}-\mathrm{Bi}_{2} \mathrm{Sr}_{2} \mathrm{CaCu}_{2} \mathrm{O}_{8+d}$ conductors can be effectively overcome by application of in situ thermo-mechanical treatment. The only problem is the price of such wires because: approximately $1 / 3$ of the cost is materials, $1 / 3$ is an intensive labour and $1 / 3$ electricity which cannot be altered and the price at $4.2 \mathrm{~K}$ and $0 \mathrm{~T}$ is estimated to be $\approx 40 € /(\mathrm{kA} \mathrm{m})$ [21]. This price will increase significantly if conductor operates at $14 \div 20 \mathrm{~K}$ range. Therefore, other PIT conductors that can deliver a similar performance at $20 \mathrm{~K}$ at substantially lower price can become superconductors of choice for hydrogen-cryomagnetic technologies or even cryogen-free technologies.

\section{4. $\mathrm{MgB}_{2}$ in situ PIT densification methods}

PIT $\mathrm{Nb}_{3} \mathrm{Sn}$ and $\mathrm{MgB}_{2}$ superconducting materials are not very different if one considers that both of them are made via in situ processes that required reactive solidliquid diffusion of elements and compounds with involved phase transformation. In the case of $\mathrm{MgB}_{2}$ it is simply the matter of $\mathrm{Mg}$ diffusion to $\mathrm{B}$ with assistance of additives such as $\mathrm{SiC}, \mathrm{C}$, and $\mathrm{Cu}$ nanoparticles to improve magnetic flux pinning at higher magnetic flux densities, whereas in case of $\mathrm{Nb}_{3} \mathrm{Sn}$ it is a solid-liquid reactive diffusion of $\mathrm{Sn}$ atoms from $\mathrm{NbSn}_{2}$ in presence of $\mathrm{Cu}$ acting as a catalyst and fine grain boundary facilitator [5] to form with $\mathrm{Nb}$ a $\mathrm{Nb}_{3} \mathrm{Sn}$ layer. The importance of technological comparison between PIT $\mathrm{Nb}_{3} \mathrm{Sn}$ and PIT $\mathrm{MgB}_{2}$ liquid $\mathrm{Mg}$ reactive infiltration process $(\mathrm{Mg}-\mathrm{RLI})[22]$ seems to 
be more relevant that comparison of $\mathrm{MgB}_{2}$ that has a tag price of $>5 € /(\mathrm{kA} \mathrm{m})$ with $\mathrm{NbTi}$ that have tag price of $1 \in /(\mathrm{kA} \mathrm{m})$.

In this section, we would conduct an analysis of methods used to improve properties of the in situ $\mathrm{MgB}_{2}$ conductors. $\mathrm{MgB}_{2}$ wires manufactured by the in situ technique, in contrast to ex situ wires, diffusing magnesium atoms to boron particles experienced $\approx 25.5 \%$ decrease in density from the initial value after cold deformation, due to the phase transformation from $\mathrm{Mg}+2(\beta-\mathrm{B}) \rightarrow$ $\mathrm{MgB}_{2}$ [23]. In case of the typical PIT process where particles of $\mathrm{Mg}$ are few tenths to hundred micrometre sizes, the formation of the resulting voids in the volume of the conductor create percolated network, Fig. 6a, weakening the electromagnetic performance of the conductors.

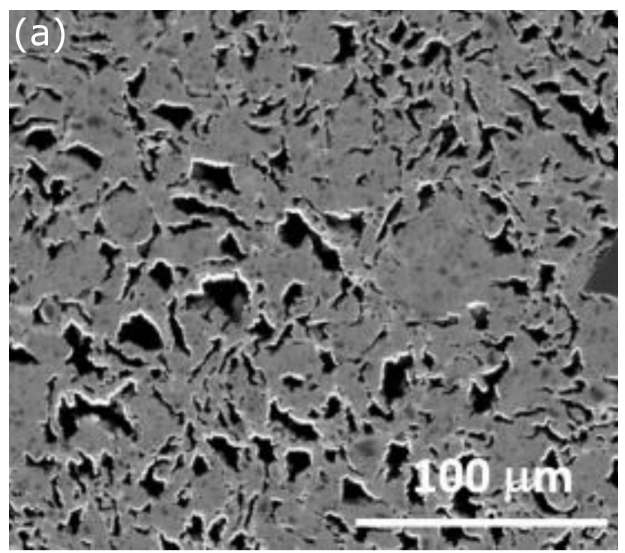

(b)

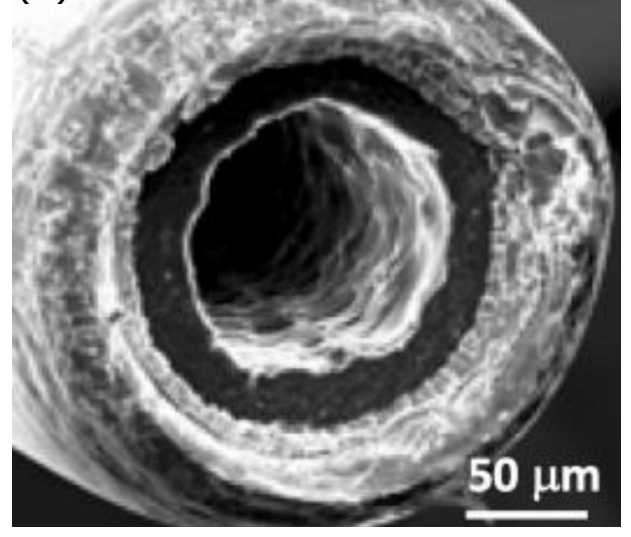

Fig. 6. SEM image of (a) the central core ex situ Monel $/ \mathrm{Ti} / \mathrm{MgB}_{2}$ PIT wire [24] (the black areas represent porosity), (b) fractured cross-section of in situ $\mathrm{Mg}$ RLI $\mathrm{MgB}_{2}$ wire showing central void after $\mathrm{Mg}$ diffused to the boron powder, the black ring represents dense $\mathrm{MgB}_{2}$ layer adopted (courtesy of G. Giunchi).

To eliminate the distributed voids created in in situ $\mathrm{MgB}_{2}$ PIT conductor a Mg-RLI process was used, where actual $\mathrm{MgB}_{2}$ monolithic ring can be created with a central single residual void instead, see Fig. 6b [22]. Critical current of such a conductor reaches the highest value, due to elimination of percolated path and fine grain structure similar to PIT $\mathrm{Nb}_{3} \mathrm{Sn}$ conductors. However, problem with unsupported central hole and rather low $J_{\text {eng }}$ remains. The ex situ wires do not suffer from such a retrograde transformation but densification and consolidation of the $\mathrm{MgB}_{2}$ powder in PIT technique in general require compaction and in most cases subsequent sintering at elevated temperatures of $800^{\circ} \mathrm{C}$ and above which narrowing down options of the materials used for the composite PIT process. However, it was well documented in literature that cold deformation of $\mathrm{MgB}_{2}$ powders in PIT wires without any sintering enabled remarkable transport critical current density value of $\mathrm{MgB}_{2}$ to reach $1 \times 10^{3} \mathrm{~A} \mathrm{~mm}^{-2}$ at $4.2 \mathrm{~K}$ [25]. But sintering of the ex situ bulks shows "solid-state self-sintering" of the $\mathrm{MgB}_{2}$ grains with dispersion of porosity in the grains, but without grain growth reaching $J_{c}=5 \times 10^{3} \mathrm{~A} \mathrm{~mm}^{-2}$ at $20 \mathrm{~K}[26]$. Such findings present an opportunity to explore the possibility of combined ex situ and in situ technologies to thermo-mechanically fuse together $\left[\left(\mathrm{MgB}_{2}\right)\right] /[(\mathrm{Mg}+2 \mathrm{~B})]$ core in PIT copper sheathed wire. (a)
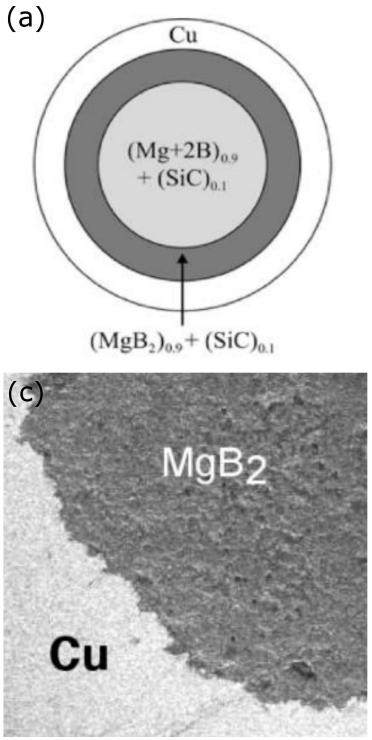
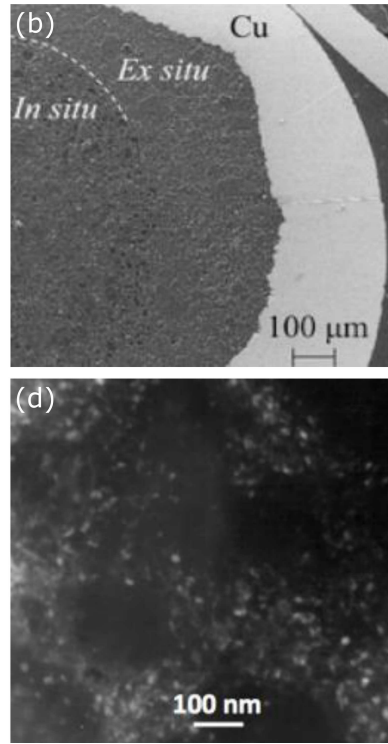

Fig. 7. Images of $\mathrm{Cu} /\left[\left(\mathrm{MgB}_{2}\right)_{0.9}(\mathrm{SiC})_{0.1}\right] /$

$\left[(\mathrm{Mg}+2 \mathrm{~B})_{0.9}(\mathrm{SiC})_{0.1}\right]$ composite wire with $\mathrm{SiC} 18 \mathrm{~nm}$ average grain size powder: (a) schematic of the overall cross-section, (b) SEM micrograph of part of the crosssection, showing the distinctive difference in morphology between ex situ and in situ cores before reaction [28], (c) SEM micrograph of $\mathrm{MgB}_{2}$ core after reaction, (d) TEM micrograph showing $\mathrm{MgO}$ nano-inclusions population in the ex situ region, indicating one of the source of artificial pinning centres embedded into the $\mathrm{MgB}_{2}$ microstructure as observed by Komori et al. [29].

As none of the above described $\mathrm{MgB}_{2}$ preparation process can avoid formation of voids (as a result of phase transformation from $\left.\mathrm{Mg}+2(\beta-\mathrm{B}) \rightarrow \mathrm{MgB}_{2}\right)$ a novel approach was adopted, similar as described in previous section, and used to hydrostatically densify $\mathrm{Ag}-\mathrm{Bi}_{2} \mathrm{Sr}_{2} \mathrm{CaCu}_{2} \mathrm{O}_{8+x}$ during sintering that results in $100 \%$ dense filaments characterised by dramatically im- 
proved $I_{c}$ almost order of magnitude. In $\mathrm{MgB}_{2}$ case metal matrix should prevent oxygen diffusion in contrast to $\mathrm{Ag}-\mathrm{Bi}_{2} \mathrm{Sr}_{2} \mathrm{CaCu}_{2} \mathrm{O}_{8+x}$ but to achieve a similar effect in terms of sheath metal softness at elevated temperatures, $\mathrm{Cu}$ matrix was chosen. Additionally, to prevent formation of the unwanted $\mathrm{MgCu}_{2}$ phase between $\mathrm{Cu}$ and $\mathrm{Mg}$ [19] and also eliminate need for diffusion barrier, a patented concept of the composite $\mathrm{Cu} /\left[\left(\mathrm{MgB}_{2}\right)_{0.9}(\mathrm{SiC})_{0.1}\right] /\left[(\mathrm{Mg}+2 \mathrm{~B})_{0.9}(\mathrm{SiC})_{0.1}\right]$ conductor was used in which a central in situ $\mathrm{Mg}+2 \mathrm{~B}$ core was surrounded by a concentric ex situ $\mathrm{MgB}_{2}$ tube acting as a diffusion barrier, Fig. 7 [27], see Fig. 7a and b.

Starting in situ powder was densified using cold isostatic pressing at pressure of $0.3 \mathrm{GPa}$ assuring better density of the central insert and higher uniformity of the external ex situ $\mathrm{MgB}_{2}$ layer. A dynamic sintering was conducted at $750{ }^{\circ} \mathrm{C}$ for 15 min under pressure of $1 \mathrm{GPa}$. From an earlier experiment, it became evident that pressure needs to be introduced before in situ formation of the $\mathrm{MgB}_{2}$ is taking place and preferentially continues during high temperature sintering to result in densified core [30].

It can be argued that in the configuration where parts of ex situ and in situ $\mathrm{Mg}-\mathrm{B}$ conductor coexist, process of $\mathrm{MgB}_{2}$ formation and co-densification of $\mathrm{MgB}_{2}$ under high pressure and short time can be very complex to achieve the desired high $I_{c}$ value across the $[e x$ situ/in situ $]$ HIP conductor, Fig. 7. Such process requires highly dynamic non-isothermal rapid sintering to satisfy infiltration of the ex situ part by some magnesium atoms as well as induce pressure on the in situ core via ex situ layer. Such sintering process must allow formation of the $\mathrm{MgB}_{2}$ and $\mathrm{Mg}$-assisted densification of the whole conductor under induced gas pressure.

Resulting microstructure of $\mathrm{MgB}_{2}$ ex situ/in situ PIT wire, Fig. 7c is not clearly understood, however, disturbed crystal structure, chemical deviation, the presence of distributed secondary non-superconducting phases, the presence of stacking faults and numerous structurally induced macro-voids as well as nano-sized $\mathrm{MgO}$ (see Fig. 7d) were also observed in thin films [29]. (Anisotropy of the electronic properties at high-angle boundaries of the crystals can all contribute to high values of critical current of the resulting $\mathrm{MgB}_{2}$ core as a whole, Fig. 8.) Volume flux pinning computer simulation has revealed co-existence of two pinning mechanisms: grain boundary and also APC in analogy to pinning mechanisms in thin films $[25,29,31]$ shifting the maximum pinning force towards the higher magnetic flux density.

\section{Conclusions}

It becomes apparent that analysed three powder-intube superconductive conductors can potentially be competitive at $14-20 \mathrm{~K}$ if novel effective thermally-assisted densification processes can be used. $\mathrm{MgB}_{2}$ at $4.2 \mathrm{~K}$ can possibly even compete with other discussed PIT conductors in the high magnetic flux density range if novel on-line densification process is developed. Hot pressing

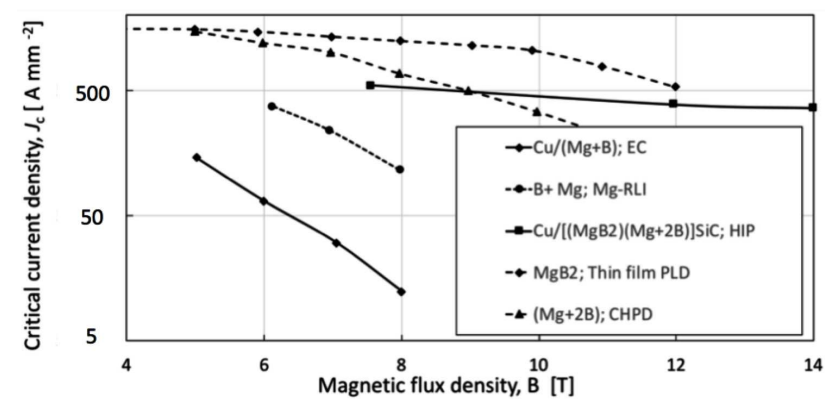

Fig. 8. Comparison of the transport current performance results of the $\mathrm{Cu}$ based wires technology (solid lines) with other PIT and thin film technologies (dotted lines), vs. magnetic flux density at $4.2 \mathrm{~K}$. The $\mathrm{PIT} \mathrm{Cu} /\left[\mathrm{MgB}_{2} / \mathrm{Mg}+2 \mathrm{~B}\right]$ hot isostatically pressed (HIP) wire performance at higher magnetic flux densities is reaching $J_{c}$ of $\mathrm{MgB}_{2}$ manufactured by cold high pressure densification (CHPD) [32], approaching values for pulse laser deposited (PLD) thin films [29] and also outperforming reactive liquid $\mathrm{Mg}$ infiltration (Mg-RLI) wires [22] as well as electromagnetically compressed (EC) copper cladded wires [31]. In this case due to complexity of comparison of the very different conductor architecture, substrate and matrix relative volume as well as $\mathrm{MgB}_{2}$ density variation, the values of the critical current density presented correspond to the actual part occupied by $\mathrm{MgB}_{2}$ superconductor..

increases density by increasing the stresses present at the particle contacts, adding plastic yielding and powerlaw creep to the pressure-less diffusional densification mechanisms.

Intensive research and development of all three conductors should continue not only for the benefit of the potential applications especially in the range of 14$20 \mathrm{~K}$ in anticipation of the emerging hydrogen cryomagnetics revolution for energy applications, but also for better understanding of influence of novel reactive thermo-mechanically assisted densification processes on microstructural and electromagnetic properties of superconducting materials. However if advanced $\mathrm{MgB}_{2}$ wires can deliver desired current density at $15-20 \mathrm{~K}$ at moderate and higher magnetic flux densities, at target cost as low as $2 € /(\mathrm{kA} \mathrm{m})$, then $\mathrm{MgB}_{2}$ will emerge as replacement PIT technology for applications benefiting from elevated temperature application margin, relying on cryogen-free, close loop helium gas cooling or even liquid hydrogen cooling.

\section{References}

[1] A. Godeke, A. den Ouden, A. Nijhuis, H.H.J. ten Kate, Cryogenics 48, 308 (2008).

[2] E. Barzi, N. Andreev, M. Bossert, V.V. Kashikhin, D. Turrioni, R. Yamada, A.V. Zlobin, AIP Conf. Proc. 1219, 183 (2010).

[3] B.A. Glowacki, W.J. Nuttall, E. Hanley, L. Kennedy, D. O'Flynn, J. Supercond. Nov. Magn. 28, 561 (2015).

[4] Filamentary A15 Superconductors, Eds. M. Suenaga, A.F. Clark, series Cryogenic Materials, Plenum Press, New York 1980. 
[5] C. Tarantini, C. Segal, Z.H. Sung, P.J. Lee, L. Oberli, A. Ballarino, L. Bottura, D.C. Larbalestier, Supercond. Sci. Technol. 28, 095001 (2015).

[6] B.A. Glowacki, Acta Phys. Pol. A 130, 531 (2016).

[7] L.R. Motowidlo, P.J. Lee, C. Tarantini, S. Balachandran, A.K Ghosh, D.C. Larbalestier, Supercond. Sci. Technol. 31, 014002 (2018).

[8] B.A. Glowacki, X-Y. Yan, D.J. Fray, G. Chen, M. Majoros, Y. Shi, Physica C 372-376, 1315 (2002).

[9] B.A. Glowacki, X-Y. Yan, D.J. Fray, G. Chen, Physica C 387, 242 (2003).

[10] G.Z. Chen, D.J. Fray, T.W. Farthing, Nature 407, 361 (2000).

[11] B.A. Glowacki, X-Y. Yan, D. Fray, G. Chen, Patent PA 43563GB.

[12] A. Ballarino, L. Bottura, IEEE Trans. Appl. Supercond. 25, 6000906 (2015).

[13] D.W. Johnson Jr., W.W. Rhodes, J. Am. Ceram. Soc. 72, 2346 (1989).

[14] B.A. Glowacki, J. Jackiewicz, J. Appl. Phys. 75, 2992 (1994)

[15] W. Lo, B.A. Glowacki, Physica C 193, 253 (1992).

[16] H. Noji, W. Zhou, B.A. Glowacki, A. Oota, Appl. Phys. Lett. 63, 833 (1993).

[17] J. Jiang, W.L. Starch, M. Hannion, F. Kametani, U.P. Trociewitz, E.E. Hellstrom, D.C. Larbalestier, Supercond. Sci. Technol. 24, 082001 (2011).

[18] D.C. Larbalestier, J. Jiang, U.P. Trociewitz, F. Kametani, C. Scheuerlein, M. Dalban-Canassy, M. Matras, P. Chen, N.C. Craig, P.J. Lee, E.E. Hellstrom, Nature Mater. 13, 375 (2014).

[19] M.P. James, B.A. Glowacki, A. Tampieri, G. Celloti, J. Mater. Sci. 32, 1409 (1997).

[20] T. Matsushita, Y. Himeda, M. Kiuchi, J. Fujikami, K. Hayashi, K. Sato, Supercond. Sci. Technol. 19, 1110 (2006)
[21] P.M. Grant, T.P. Sheahen, presented at the Applied Superconductivity Conf., Palm Desert (CA), USA 1998.

[22] B. Brunner, P. Kovác, M. Reissner, I. Hušek, T. Melišek, E. Pardo, Physica C 505, 39 (2014).

[23] B.A. Glowacki, M. Majoros, M. Vickers, M. Eisterer, S. Toenies, H.W. Weber, M. Fukutomi, K. Komori, K. Togano, Supercond. Sci. Technol. 16, 297 (2003).

[24] M.N. Kutukcu, S. Atamert, J.-L. Scandella, R. Hopstock, A.C. Blackwood, C. Dhulst, J. Mestdagh, A. Nijhuis, B.A. Glowacki, IEEE Transactions on Applied Superconductivity 28, 6200704 (2018).

[25] G. Grasso, A. Malagoli, C. Ferdeghini, S. Roncallo, V. Braccini, A.S. Siri, M.R. Cimberle, Appl. Phys. Lett. 79, 230 (2001).

[26] H. Tanaka, A. Yamamoto, J. Shimoyama, H. Ogino, K. Kishio, Supercond. Sci. Technol. 25, 115022 (2012).

[27] B.A. Glowacki, A. Morawski, Patent WO2008122802.

[28] A. Kario, A. Morawski, B.A. Glowacki, T. Lada, M. Smaga, R. Diduszko, D. Kolesnikov, A.J. Zaleski, A. Kondrat, D. Gajda, Acta Phys. Pol. A 111, 693 (2007).

[29] K. Komori, K. Kawagishi, Y. Takano, H. Fujii, S. Arisawa, H. Kumakura, M. Fukutomi, K. Togano, Appl. Phys. Lett. 81, 1047 (2002).

[30] M. Woźniak, B.A. Glowacki, Supercond. Sci. Technol. 27, 035008 (2014).

[31] A. Matsumoto, Y. Kobayashi, K. Takahashi, H. Kumakura, H. Kitaguchi, Appl. Phys. Expr. 1, 021702 (2008).

[32] G.Z. Li, K.M. Reddy, J.B. Zwayer, M.A. Kuldell, M.A. Susner, Y. Yang, M.D. Sumption, J.J. Yue, M.A. Rindfleisch, M.J. Tomsic, C.J. Thong, E.W. Collings, IEEE Trans. Appl. Supercond. 23, 6200204 (2013). 